\title{
User Experience Measurement using Augmented Reality Application in Learning 4.0
}

\author{
Derisma $^{1}$, Muhammad Hafiz Hersyah ${ }^{2}$ \\ \{derisma@fti.unand.ac.id ${ }^{1}$, mohammadhafizhersyah@it.unand.ac.id² \\ 1,2 Department of Computer System, Faculty of Information Technology, Universitas Andalas, \\ Padang, Indonesia
}

\begin{abstract}
This Research aims to acquire the effectivity of learning media based on augmented reality on Multimedia System Course in Computer System Department, Information Technology Faculty, Andalas University. The research was commencing initialization by data acquisition by the online questioner. The result is the user assessment on six application quality that is: Attractiveness, Perspicuity, Efficiency, Dependability, Stimulation, and Novelty. The result shows that in a range between -3 and 3 , the application possesses decent result by achieving 1.30 for Attractiveness, 1.12 for Perspicuity, 1.15 for Efficiency, 1.10 for Dependability, 1.43 for Stimulation and 0.74 for Novelty. The benchmarking result shows that positives rating average mark is in the above averages. Based on the analysis in this research, Augmented Reality Application increase the effectivity of learning 4.0 .
\end{abstract}

Keywords: Learning 4.0, Augmented Reality, User Experience Questionnaire.

\section{Introduction}

In previous research, there was quite a lot of Augmented Reality (AR) implementation technology has been done especially in the specific fields such as education, including Human Anatomy Learning Systems [1], medical training simulators [2] Learning English [3], Vocational Education and Training [4], engaging visitors of a literary museum [5], creative design course [6], electronic storybooks on elementary school [7], nursing education [8] virtual Interactive Laboratory [9], Human Body Anatomy Learning [10]. The use of AR technology in the world of education makes the learning process easier, clearer, and more interactive [7], [8], [11]-[14] Augmented Reality has become a pioneer in how to deliver information because it combines text, images, videos, 3-dimensional models, which cannot be delivered through books, or other 2-dimensional multimedia images such as videos and teaching aids [7].

Semester Learning Plans (RPS) of Multimedia System courses at the Computer Systems Department of the Faculty of Technology, Andalas University at two final meetings 14 and 15 discuss the topic of Augmented Reality and its application. At these meeting, students were told to engage Augmented Reality products for learning on computer systems that emphasized the mastery of hardware over software. Augmented Reality applications can be useful for users, especially students, in understanding computer hardware. Learning hardware by relying on textbooks is difficult to understand [15]. As a result, there are still many who do not know 
computer hardware in more detail and its functions, which is caused by limited practical facilities and the absence of props that support to provide the needed illustrations, while if purchased the original is still relatively expensive. Often the learning material available in the book is not sufficient enough to assist students to understand the object well. Students and students will find it difficult to visualize 2-dimensional images into three dimensions to understand certain illustrations/abstracts. With the existence of Augmented Reality Technology, it can be a solution in applying the teaching and learning process especially in computer majors education, which is more interactive using 3D compared to the previous version, namely 2D media.

Based on the problems mentioned, it is necessary to conduct research on the effectiveness of using Augmented Reality-based learning media in hardware learning. This research will be conducted using User Experience Questionnaire (UEQ) because UEQ can measure the effectiveness of learning media based on Attractiveness, Pragmatic Quality, and Hedonic Quality [16]. The development of the UEQ questionnaire in assessing the quality of a product is based on (1) ISO 9241-10 to assess product quality based on usability and (2) ISO 9241-11 to assess product quality based on criteria of effectiveness or efficiency. UEQ allows a quick assessment carried out by users that include the impression of more comprehensive user experience. This allows users to express the feelings, impressions, and attitudes that arise when experiencing the product being investigated in a very simple and direct way.

Learning 4.0 is a response from industry 4.0, where humans and technology are harmonized to enable new possibilities. Fisk [17] explained that learning for students is not only limited skills and knowledge but to identify resources to learn skills and knowledge. Learning is built from the environment of students in learning and tracking the performance of students through adjustments based on data. Peers become very important in learning 4.0. Students learn together while teachers take on the role of facilitator in learning. Learning 4.0 refers to 9 trends:

1) Learning can be done anywhere and anytime (learning can be taken place anytime anywhere).

2) Learning is carried out personally (learning will be personalized to individual students).

3) Students have the opportunity to determine the material to be learned (students have a choice in determining how they want to learn).

4) Project-based learning (students will be exposed to more project-based learning).

5) Direct learning through field experiences such as internships, guidance on projects, and collaborative projects (students will be exposed to more hands-on through field learning experiences such as internships, mentoring projects, and collaborative projects).

6) Learning in the form of application of practice (students will be exposed to data interpretation in which they are required to apply their theoretical knowledge to numbers and use of their reasoning skills to make inferences based on logic and trends from given sets of data).

7) Learning is evaluated not tested (students will be assessed differently, and the conventional platforms to assess students may become irrelevant or insufficient).

8) Modular learning (students' opinions) will be considered in designing and updating the curriculum.

9) Ownership of learning by students (students will become more independent in their own learning, thus forcing teachers to assume a new role as facilitators who will guide students through their learning process). 
According to Ronald T. Azuma, [18] defines Augmented Reality (AR) as the incorporation of real and virtual objects in a real environment, runs interactively in real-time (real-time), and there is integration between objects in $3 \mathrm{D}$, namely virtual objects integrated into the real world. Combining real and virtual objects is possible with appropriate display technology, interactivity is possible through certain input devices, and good integration requires effective tracking.

Usability is the extent to which the feasibility of a system is based on effectiveness, efficiency, and satisfaction in certain contexts. The importance of usability to measure the quality of the feasibility of a system that leads to several testing methods. UEQ or User Experience Questionnaire [19], including one questionnaire that can be used in usability tests to measure the level of User Experience of a product. The aim of UEQ is to enable swift assessment by end-users that includes the impression of more comprehensive user experience. This should allow the user to express the feelings, impressions, and attitudes that arise when experiencing the product being investigated in a very simple and direct manner. UEQ can be downloaded at www.ueq-online.org. There are six scales with a total of 26 elements categorized based on the measurement scales found in UEQ [20]. Each item can be assessed on a 7-point Likert scale. The scale range is between -3 (very bad) and +3 (very good). User Experience Scale in the questionnaire, namely:

a. Attractive

How big is the appeal of a product? For example: good or bad, attractive or not attractive.

b. Perspicuity (Clarity)

How big is the clarity of a product? For example: easy to understand or difficult to understand.

c. Efficiency

How much users can complete their tasks without a large or efficient effort. For example: fast or slow, practical or impractical.

d. Dependability

How much accuracy is felt by the user through the control he has. For example: predictable or unpredictable, supporting, or obstructing.

e. Stimulation (Stimulation)

How much motivation to use the product. For example: useful or less useful, interesting or uninteresting.

f. Novelty (Novelty)

How big is the novelty of the product? For example: creative or not creative, conservative, or innovative.

Attractiveness is a pure valence dimension, not including any aspect of quality. Clarity, efficiency, and accuracy belonging to the pragmatic quality aspects that are goal-oriented so that the user must do the task to achieve the goal. While stimulation and novelty is a hedonic quality aspect that is not goal-oriented, so users only do the task without needing to reach the goal. 


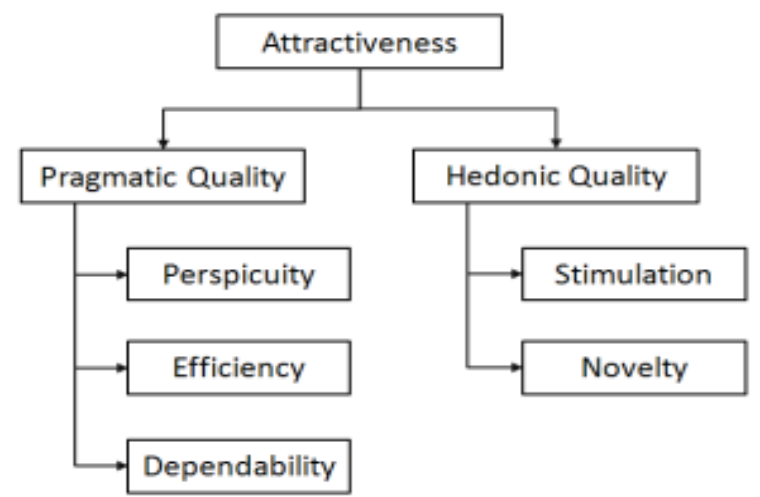

Fig. 1. UEQ Chart

UEQ data will be processed automatically if the data is entered into UEQ Data Analysis Tools. Which is made using Microsoft Excel devices, and can be downloaded together with the questionnaire file. The data will undergo a process of data transformation, calculation of average values, calculation of variance and standard deviation, and calculation of confidence intervals and comparisons with benchmark data sets [18]. The benchmark data set is a data collection from 18483 participants based on 401 studies of various products, such as business applications, web pages, web stores, and social networks. Validity and reliability of calculating devices can also be analyzed by looking at the results of correlation calculations and Cronbach's alpha. That way, researchers can see whether the data obtained is feasible and reliable as a basis for measuring User Experience level.

\section{Methods}

The several stages of this research are starting from the study of literature. In this stage, reference searches, basic theoretical sources, and supporting information were carried out to strengthen the research studies conducted. By doing this initial stage, it is expected to be able to understand better the concept of Learning 4.0, Augmented Reality, User Experience Questionnaire and other supporting concepts used in the next stage of the research, namely designing, data collection, data processing and results in analysis.

\section{Learning Design}

The system developed is learning 4.0, where student learning wherever and whenever students want to carry out the learning process. Students learn together while the lecturers take on the role of facilitators. Students can utilize their smartphone to access learning on Augmented Reality Books that have been provided by the lecturer. In this application, 3D objects are generated based on the original image so that the user is like seeing the original object. The advantages in the application generated by the object can be rotated so that the object can be seen clearly on each side. So it is expected that the resulting application can also provide many benefits to users to get to know and know the computer system hardware form clearly and easily understood. 


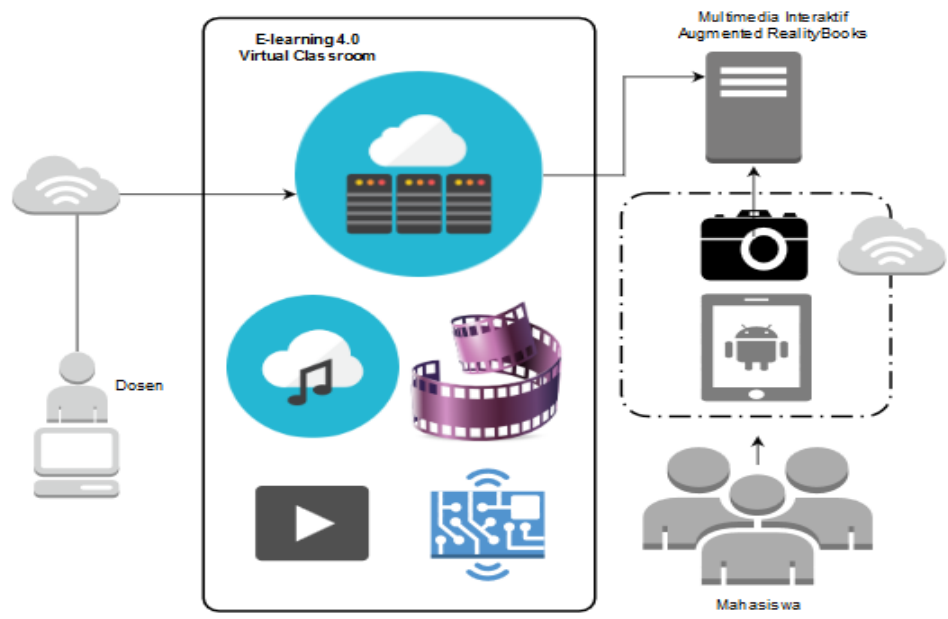

Fig. 2. Augmented Reality Learning Design

\section{Questionnaire Design}

This research was carried out in the Andalas University and other universities, majoring in computer systems, especially students taking courses in Multimedia Systems. This research was conducted by making a questionnaire that was filled out directly by students on a smartphone, PC, tablet, or desktop. The link for filling out the questionnaire was distributed to the participants. Through this research, usability measurements were carried out to get the level of understanding and difficulty of the user in using Augmented Reality devices. This study measures the level of use of the application through two criteria, namely Nielsen's usability criteria, namely learn ability, efficiency, memorability, errors, and satisfaction and user experience questionnaire (UEQ). The research methodology was carried out in steps such as those in Figure 1. The primary data collection method was carried out by a questionnaire/questionnaire through survey media to obtain data. On UEQ criteria, the variable measurement scale refers to the experience of users who have used healthy mental applications, with 26 questions and on a scale of 1-7. Number 1 does not always represent a bad statement, and number 7 does not always represent a positive statement. 


\begin{tabular}{|c|c|c|c|c|}
\hline \multirow{2}{*}{$\begin{array}{c}N_{0} \\
1 \\
\end{array}$} & \multirow{2}{*}{\begin{tabular}{|c|} 
Group \\
Attractiveness \\
\end{tabular}} & \multicolumn{3}{|c|}{ Item (No. Questionnaire) } \\
\hline & & 1 & annoying & enjoyable \\
\hline & & 12 & good & bad \\
\hline & & 14 & unlikable & pleasing \\
\hline & & 16 & unpleasant & pleasant \\
\hline & & 24 & attractive & unattractive \\
\hline & & 25 & friendly & unfriendly \\
\hline \multirow[t]{4}{*}{2} & Dependability & 2 & unp redictable & predictable \\
\hline & & 4 & obstructive & supportive \\
\hline & & 13 & secure & not secure \\
\hline & & 21 & $\begin{array}{c}\text { meets } \\
\text { expectations }\end{array}$ & does not meet expectations \\
\hline \multirow[t]{4}{*}{3} & Efficiency & 9 & fast & slow \\
\hline & & 20 & inefficient & efficient \\
\hline & & 22 & impractical & practical \\
\hline & & 23 & organized & cluttered \\
\hline \multirow[t]{4}{*}{4} & Perspicuity & 8 & $\begin{array}{c}\text { not } \\
\text { understandable }\end{array}$ & understandable \\
\hline & & 11 & easy to learn & difficult to learn \\
\hline & & 17 & complicated & easy \\
\hline & & 19 & clear & confusing \\
\hline \multirow[t]{4}{*}{5} & Stimulation & 5 & valuable & inferior \\
\hline & & 6 & boring & exciting \\
\hline & & 7 & not interesting & interesting \\
\hline & & 18 & motivating & demotivating \\
\hline \multirow[t]{4}{*}{6} & Novelty & 3 & creative & dull \\
\hline & & 10 & inventive & conventional \\
\hline & & 15 & usual & leading edge \\
\hline & & 26 & conservative & innovative \\
\hline
\end{tabular}

\begin{tabular}{|c|c|c|c|}
\hline annoying & 0000000 & enjoyable & 1 \\
\hline not understandablè & 0000000 & understandable & 2 \\
\hline creative & 0000000 & dull & 3 \\
\hline casy to learn & 0000000 & difficult to learn & 4 \\
\hline valuable & 0000000 & inferior & 5 \\
\hline boring & 0000000 & exciting & 6 \\
\hline not interesting & 0000000 & interesting & 7 \\
\hline unpredictable & 0000000 & predictable & 8 \\
\hline fast & 0000000 & slow & 9 \\
\hline inventive & 0000000 & conventional & 10 \\
\hline obstructive & 0000000 & supportive & II \\
\hline good & 0000000 & bad & 12 \\
\hline complicated & 0000000 & tasy & 13 \\
\hline unlikable & 0000000 & pleasing & 14 \\
\hline usual & 0000000 & leading edge & 15 \\
\hline unpleasant & 0000000 & plessant & 16 \\
\hline sceure & 0000000 & not sccure & 17 \\
\hline motivating & 0000000 & demotivating & 18 \\
\hline meets expectations & 0000000 & does not meet expectations & 19 \\
\hline inefficient & 0000000 & efficient & 20 \\
\hline clear & 0000000 & confusing & 21 \\
\hline impractical & 0000000 & practical & 22 \\
\hline organized & 0000000 & duttered & 23 \\
\hline altractive & 0000000 & unattractive & 24 \\
\hline friendly & 0000000 & unffiendly & 25 \\
\hline conservative & 0000000 & innovative & 26 \\
\hline
\end{tabular}

Fig. 3.User Experience Questionnaire (UEQ)

\section{Data Gathering}

Respondents from this study were students who took Multimedia Systems courses totaling 77 people. The respondents are generally 19-20 years old consisting of several sub-districts ranging from 13th generation 1 person $(1,2 \%)$, 14th generation 2 people $(2,59 \%)$, 15th generation 7 people $(9,09 \%)$, class 1624 people $(31,16 \%)$ and generation 1743 people $(55$, $8 \%$ ) with all levels of education S1. The assignments are given to students of class multimedia systems who come from students who already understand the android application so that they will no longer experience difficulties when carrying out the tasks of the questionnaire. The scenario of respondent assignments can be seen in the list below:

1. Enter the Augment application

2. Select explore.

3. Type and search Arduino.

4. Select ArduinoUnoRev3.

5. Observe in more detail by selecting $3 \mathrm{~d}$ view, rotate, flash.

6. Press create a tracker menu.

7. Take a book or paper that contains a schematic of the ArduinoUnoRev3 diagram.

8. Point the cellphone's camera to the right position marked by the appearance of a tap to capture sentence.

9. Rotate the paper so that you can see all parts of Arduino. 


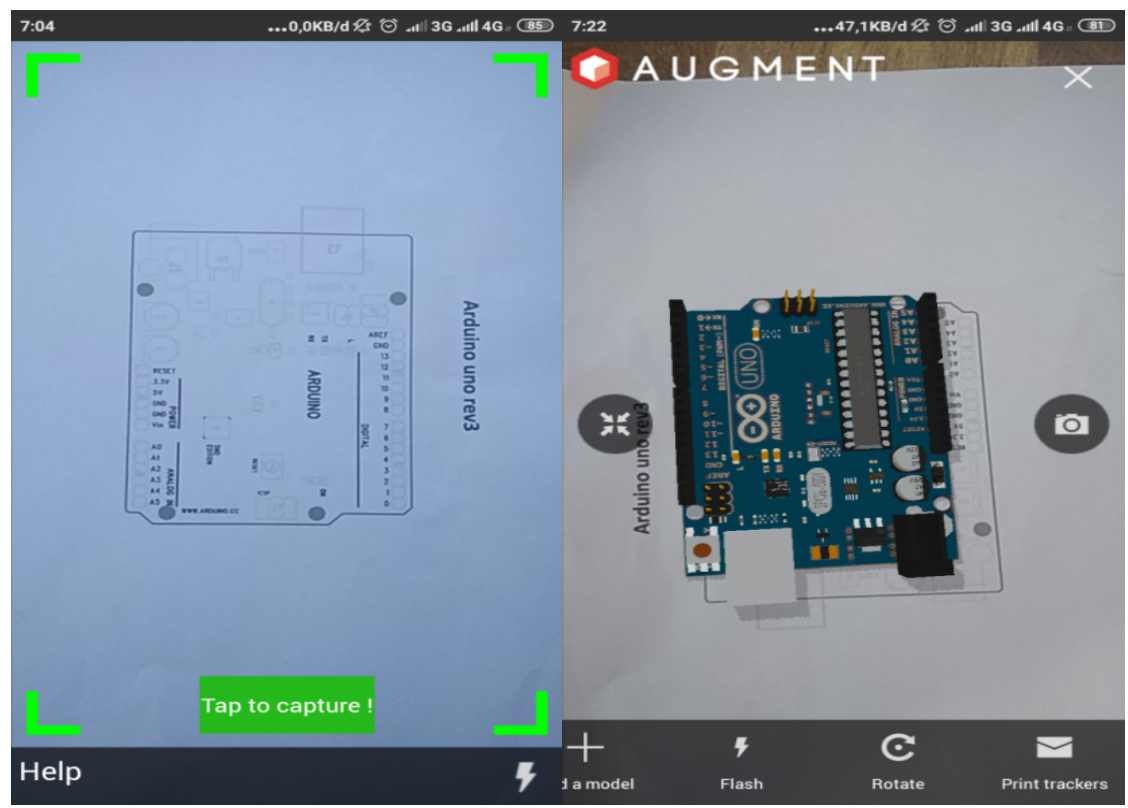

Fig. 4.Respondent Scenario

\section{Data Processing}

After the data or questionnaire is shared online with Google Form, then the data processing stages are carried out as follows:

1. Re-examination of the questionnaire to determine how much data is missing.

2. After the data is clean, the frequency can be obtained from the data.

3. Recalculating the respondent's answers to the results of the questionnaire and processing them.

4. Test the reliability and validity of the data.

5. Benchmark measurement results.

\section{Results and Discussion}

Users who have given a review of each item, then the average group category will be obtained, which can be seen in Table 1. Validation tests are conducted to see whether the data obtained is sufficiently valid for each criterion. This validation test is done by calculating the average value of item-total coleration from each question in the criteria group using Cronbach correlation, if the average value is $>R$ table value, then the question in the criteria group is considered "valid." The rabelled value is obtained from table $\mathrm{R}$ with the free degree $\mathrm{n}-2$ where $\mathrm{n}$ is the number of respondents, so the value used in this case is table $\mathrm{r}$ with a free degree 75 (77-2). From the $\mathrm{R}$ table, it is found that the Cronbach alpha value is 0.96 . It is said a reliable system if the alpha value is greater than 0 . 60. With an alpha value of 0.96 , the system question item used to measure the degree of reliability of the Augment application. An application can be said to be reliable. Here a 5\% confidence interval for the average scale and a single item average is shown. The confidence interval is a measure for the accuracy of the average scale estimate. The smaller the confidence interval, the higher the accuracy of the estimate, and the more you can trust the results. The width of the confidence interval depends 
on the amount of data available and on how consistently people value the product being evaluated. The more consistent their opinions, the smaller the confidence interval.

Table 1. UEQ Result

\begin{tabular}{|c|c|c|c|c|c|c|c|c|}
\hline \multicolumn{7}{|c|}{ Confidence intervals $(\mathrm{p}=\mathbf{0 . 0 5})$ per scale } & \multirow[b]{2}{*}{$\begin{array}{c}\text { Cronbachs } \\
\text { Alpha }\end{array}$} & \multirow[b]{2}{*}{$\begin{array}{c}\text { Comparisson to } \\
\text { benchmark }\end{array}$} \\
\hline Scale & Mean & $\begin{array}{l}\text { Std. } \\
\text { Dev. }\end{array}$ & $\mathbf{N}$ & Confidence & \multicolumn{2}{|c|}{$\begin{array}{c}\text { Confidence } \\
\text { interval }\end{array}$} & & \\
\hline Attractiveness & 1.296 & 0.865 & 77 & 0.193 & 1.102 & 1.489 & 0.82 & Above average \\
\hline Perspicuity & 1.120 & 0.997 & 77 & 0.223 & 0.898 & 1.343 & 0. & Average \\
\hline Efficiency & 1.153 & 0.847 & 77 & 0.189 & 0.964 & 1.342 & 0.75 & Above Average \\
\hline Dependability & 1.097 & 0.942 & 77 & 0.210 & 0.887 & 1.308 & 0.60 & Below Average \\
\hline Stimulation & 1.431 & 0.897 & 77 & 0.200 & 1.231 & 1.632 & 0.82 & Good \\
\hline Novelty & 0.744 & 1.005 & 77 & 0.225 & 0.520 & 0.969 & 0.66 & Above Average \\
\hline
\end{tabular}

Each item in UEQ which originally had a scale values 1 to 7 was transformed into a UEQ scale which was a scale of -3 (very negative) to +3 (very positive). After testing is done, the results obtained in terms of Attractiveness, Perspicuity, Efficiency, Dependability, Stimulation, Novelty is also stated to be good close to +2 . From the graph it can be seen to produce very small interval lines (black lines), with this it can be said that the sample data used is sufficient and can include population parameters if several trial evaluations are carried out, the assessment will remain in that small range.

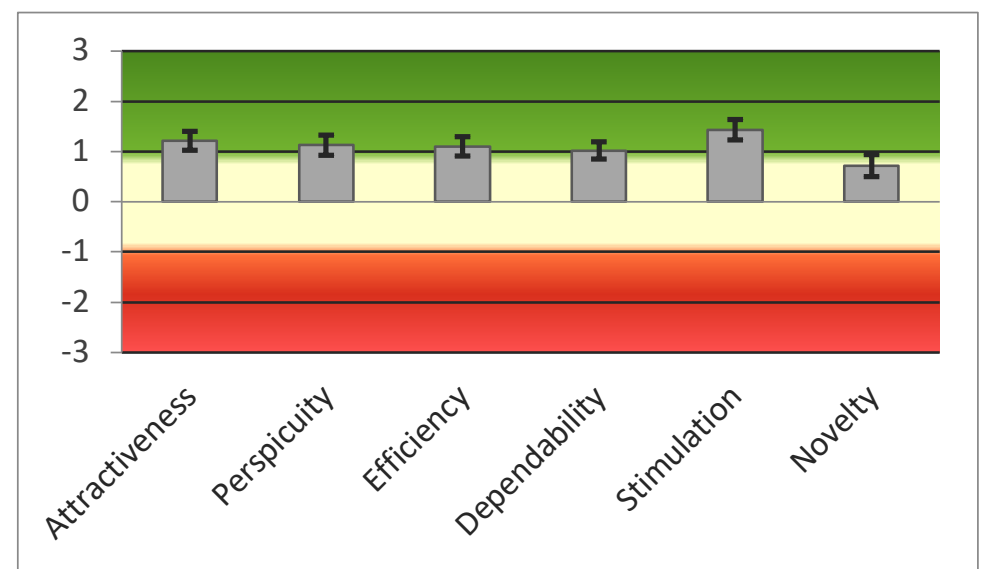

Fig. 5. .Confidence Intervals per Scale UEQ

Benchmarks are very helpful in situations where a product is measured for the first time with UEQ, i.e., where there are no previous evaluation results available for comparison. The benchmark data set is a data set from 18483 participants based on 401 studies. 


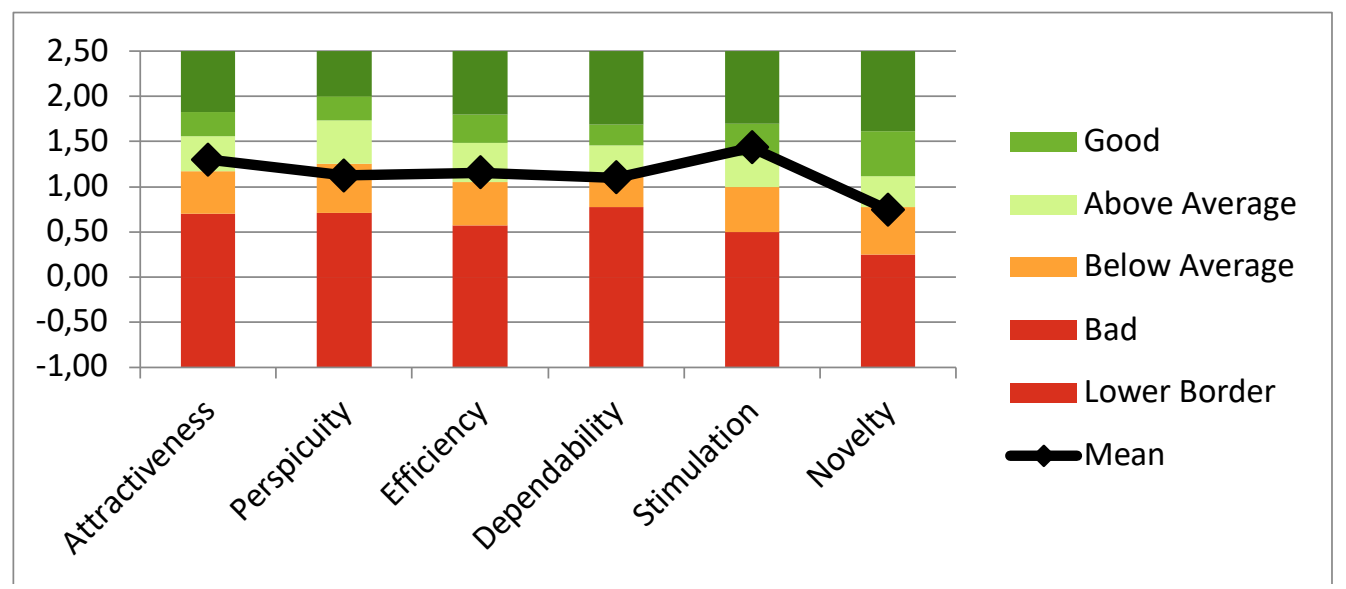

Fig. 6. .Assessment Result Benchmark

Based on the graph in figure 5 . it can be seen that the highest value lies in the stimulation quality category, meaning that each user feels constantly motivated and feels he wants to continue to use it. The system built is able to attract and stimulate users to re-use this system on other occasions and times. For clarity above average, it means that the system has concepts, objectives, and methods of use that are very clear and easily understood by the user. Mapping for all scales as a result of testing the benchmark value also shows that the system built is above the average. The value of accuracy is below the average because this application is still slow when run; this depends on the ability of the smartphone of the student.

\section{Conclusion}

Based on the results of all data processing and analysis that has been done in this study, it can be concluded that the AR media can increase the effectiveness of teaching. The use of educational media using Augmented Reality can directly provide 4.0 learning wherever and whenever students want to carry out the learning process. AR Learning Media can visualize abstract concepts for understanding and structuring an object model allowing AR as a more effective media in accordance with the objectives of the learning media. After the application has been tested using UEQ in six application quality categories, the following values are obtained:

1) Attractiveness, which is about feeling good or bad overall when using a 1.30 app that falls into the Above average category.

2) Efficiency in terms of how easy a user is to use in a short time of 1.15 that is also in the Above Average range.

3) Dependability and Novelty of software that has been created, which is new for users with 0.74 , which is also in the Above Average range.

4) Perspicuity regarding user convenience and accuracy of accurate handling value, 1.12 which is within range Above Average.

5) Stimulation is about how motivated users are to continue using excellent software with a value of 1.43 that is in a good range. 


\section{References}

[1] Kurniawan, M. H., \& Witjaksono, G. (2018). ScienceDirect ScienceDirect Human Anatomy Learning Systems Using Augmented Reality on Human Anatomy Learning Systems Using Augmented Reality on Mobile Application Mobile Application. Procedia Computer Science, 135, 80-88. https://doi.org/10.1016/i.procs.2018.08.152

[2] Wesiak, G., Steiner, C. M., Moore, A., Dagger, D., Power, G., Berthold, M., ... Conlan, O. (2014). Computers \& Education Iterative augmentation of a medical training simulator: Effects of affective metacognitive scaffolding. Computers \& Education, 76, 13-29. https://doi.org/10.1016/j.compedu.2014.03.004

[3] Hsu, T. C. (2017). Learning English with Augmented Reality: Do learning styles matter? Computers and Education, 106, 137-149. https://doi.org/10.1016/j.compedu.2016.12.007

[4] Bacca, J., Baldiris, S., Fabregat, R., Kinshuk, \& Graf, S. (2015). Mobile Augmented Reality in Vocational Education and Training. Procedia Computer Science, 75(Vare), 49-58. https://doi.org/10.1016/j.procs.2015.12.203

[5] Fenu, C., \& Pittarello, F. (2018). Svevo tour: The design and the experimentation of an augmented reality application for engaging visitors of a literary museum. International Journal of Human Computer Studies, 114(February), 20-35. https://doi.org/10.1016/j.ijhcs.2018.01.009

[6] Wei, X., Weng, D., Liu, Y., \& Wang, Y. (2015). Teaching based on augmented reality for a technical creative design course. Computers and Education, 81, 221-234. https://doi.org/10.1016/j.compedu.2014.10.017

[7] Kao, G. Y. M., Tsai, C. C., Liu, C. Y., \& Yang, C. H. (2016). The effects of high/low interactive electronic storybooks on elementary school students' reading motivation, story comprehension and chromatics concepts. Computers and Education, 100, 56-70. https://doi.org/10.1016/j.compedu.2016.04.013

[8] Chang, S., \& Hwang, G. (2018). Computers \& Education Impacts of an augmented reality-based fl ipped learning guiding approach on students 'scienti fi c project performance and perceptions. Computers \& Education, 125(June), 226-239. https://doi.org/10.1016/j.compedu.2018.06.007

[9] Torres, F., Tovar, L. A. N., \& Egremy, M. C. (2015). Virtual Interactive Laboratory Applied to High Schools Programs. Procedia Computer Science, 75(Vare), 233-238. https://doi.org/10.1016/j.procs.2015.12.243

[10] Layona, R., Yulianto, B., \& Tunardi, Y. (2018). Web based Augmented Reality for Human Body Anatomy Learning. Procedia Computer Science, 135, 457-464. https://doi.org/10.1016/j.procs.2018.08.197

[11] Iftene, A., Iftene, A., \& Trandab, D. (2018). ScienceDirect ScienceDirect ScienceDirect Enhancing the of through Augmented the Attractiveness Attractiveness of Learning Learning through Augmented Reality Reality Enhancing the Attractiveness of Learning through Augmented. Procedia Computer Science, 126, 166-175. https://doi.org/10.1016/j.procs.2018.07.220

[12] Zhou, Y., Ji, S., Xu, T., \& Wang, Z. (2018). Promoting Knowledge Construction: A Model for Using Virtual Reality Interaction to Enhance Learning. Procedia Computer Science, 130, 239-246. https://doi.org/10.1016/j.procs.2018.04.035

[13] Yip, J., Wong, S., Yick, K., Chan, K., \& Wong, K. (2019). Computers \& Education Improving quality of teaching and learning in classes by using augmented reality video. Computers \& Education, 128(April 2018), 88-101. https://doi.org/10.1016/j.compedu.2018.09.014

[14] Sampaio, D., \& Almeida, P. (2016). Pedagogical Strategies for the Integration of Augmented Reality in ICT Teaching and Learning Processes. Procedia Computer Science, 100, 894-899. https://doi.org/10.1016/j.procs.2016.09.240

[15] Rayda, M. F., Haryanto, E. V., Setiawan, A., Teknik, J., Universitas, I., Utama, P., ... Komputer, H. (n.d.). Implementasi Augmented Reality Pada Hardware Komputer Berbasis Android. 109-117.

[16] Wulandari, I. R. (2018). Pengukuran User Experience Pada E-Learning Di Lingkungan Universitas Menggunakan User Experience Questionnaire (UEQ). Jurnal Mantik Penusa, 2(2), 146. 
[17] Fisk, P. (2017). Education $4.0 \ldots$ the future of learning will be dramatically different, in school and throughout life. Retrieved from http://www.thegeniusworks.com/2017/01/future-education-youngeveryone-taught-together

[18] Azuma, Ronald T., 1997. "A Survey of Augmented Reality." Presence: Teleoperators andVirtual Environments 6 (4): 355-385.

[19] Laugwitz, B., Held, T., and Schrepp, M. (2008). Construction and evaluation of a user experience questionnaire. In Holzinger, A., editor, HCI and Usability for Education and Work, volume 5298 of Lecture Notes in Computer Science, pages 63-76. Springer Berlin Heidelberg, Berlin, Heidelberg

[20] Rauschenberger, M., et al. (2013). "Efficient measurement of the user experience of interactive products. How to use the user experience questionnaire (ueq). example: spanish language version." IJIMAI 2(1): 39-45. 